\title{
A Concept Analysis of Decision-Making by Families in Critical Life Situations
}

\author{
Chiyoko Kimura', Ruriko Kidachi ${ }^{2}$ \\ ${ }^{1}$ Department of Nursing Science Doctoral Course, Graduate School of Health Sciences, Hirosaki University, \\ Hirosaki, Japan \\ ${ }^{2}$ Department of Nursing Science, Graduate School of Health Sciences, Hirosaki University, Hirosaki, Japan \\ Email: chiyoko-kimura@aomoricgu.ac.jp
}

How to cite this paper: Kimura, C. and Kidachi, R. (2019) A Concept Analysis of Decision-Making by Families in Critical Life Situations. Open Journal of Nursing, 9 , 1123-1137.

https://doi.org/10.4236/ojn.2019.911082

Received: September 28, 2019

Accepted: November 25, 2019

Published: November 28, 2019

Copyright $\odot 2019$ by author(s) and Scientific Research Publishing Inc. This work is licensed under the Creative Commons Attribution International License (CC BY 4.0).

http://creativecommons.org/licenses/by/4.0/

\begin{abstract}
Background: In 2017, the elderly made up $27.3 \%$ of Japan's population, accounting for $57.2 \%$ of all ambulance trips. When an elderly person is in a critical life situation, it is difficult to ascertain their decisions about treatment choices, and for family members who become surrogate decision-makers, this is a grave responsibility. Aim: This study aimed to shed light on the constructs that support decision-making by family members and medical staff in critical situations, and to investigate decision-making by families of the elderly in critical situations. Method: We selected 29 papers published in Japan and elsewhere that focused on families involved in treatment decisions in critical life situations and analyzed them using Rodgers' concept analysis approach. Results: From 475 codes, we extracted six attributes, four antecedents, and four consequences. The unusual setting of the "critical care unit", lack of time, and unstable psychological state are all considered by family members making treatment decisions, along with the patient's prognosis, their relationship with the patient, conjecture about the patient's wishes, and taking other family member's views into account. Medical staff supports the family throughout the process, through provision of treatment, preparing family members to face reality, empathizing with the difficulty of decision-making, building relationships with family members, monitoring the decision-making process, and being attentive to family members' feelings until the end. Conclusion: Our results indicate the importance of advance confirmation of patients' wishes, and the role played by cultural context and family relations in decision-making by family members of the elderly.
\end{abstract}

\section{Keywords}

Decision-Making, Life Crisis, Treatment Choices, Families, Medical Staff 


\section{Introduction}

In Japan, the world's top country for longevity, $27.3 \%$ of the population in 2017 was elderly according to official reports. High rates of healthcare usage in a long-lived society are inevitable; however, it is notable that the elderly account for a substantial $57.2 \%$ of all ambulance trips [1]. Research has shown that cardiovascular diseases, such as heart disease and cerebrovascular disease, are the largest reason for ambulance transportation of the elderly, at 20.6\% [2]. Ambulance services are also required in cases of sudden, unexpected accidents and the onset of serious illness.

In clinical settings, it is often difficult to perform medical examinations on the elderly due to such factors as decline in cognitive functions, atypical symptoms and test findings, multiple disorders, decline in organ reserve ability, and worsening of symptoms [3], as well as to confirm the patient's wishes. In recognition of this situation, the Japanese Ministry of Health, Labor, and Welfare issued a revised version of its "Guidelines on the Decision-Making Process in End-of-Life Care" (henceforth, "Guidelines") in 2018 [4]. According to the Guidelines, when patients cannot make decisions for themselves, or if it cannot be trusted that what they decide is really what they want, the family is entrusted with primary decision-making. Considering the diversity of family relationships, the best option for the patient should be determined collaboratively between family members and the medical team, including nurses. Regardless of support provided by medical professionals, surrogate decision-making entrusted to family members is a grave responsibility, and nurses play a critical role in supporting treatment choices by families who are surrogate decision-makers, including the provision of emotional care.

Prior studies in the fields of emergency medicine and critical care mention strong experiences of "wanting to help" [5] [6], strength of family relationships [7], and proposals by medical professionals [8], as factors affecting treatment choices by surrogates. When families act as surrogates for choosing treatment, differences in thinking and emotions rise to the surface [9] [10], and one in three surrogate decision-makers experiences psychological after-effects such as regret, which linger for months after the patient's death [11]. Cases where the patient is transported by ambulance present a particular set of challenges, such as whether the treatment selected was in line with the patient's wishes [12], whether life-prolonging treatment was selected with full understanding of the consequences [13], and whether the treatment given deviated from the plan the family and attending physician had prepared [14].

While research concerning problems related to the choice of treatment by families of geriatric patients in critical life situations that must be solved has increased in Japan in recent years, there have not been many such studies. In order to develop nursing interventions to address these challenges, it is vital to conduct patterned and systematic reviews of prior studies, without singling out geriatric patients, to find concepts linked to family decision-making when choosing 
treatment in critical life situations, and to then study the characteristics in geriatric patients themselves. The current study focuses on how these concepts change over time and in different contexts. To do so, we used Rodgers' [15] approach to concept analysis, which aims to shed light on the characteristics of concepts from a philosophical viewpoint.

\subsection{Terms and Definitions}

Person in a critical life situation: The Japan Academy of Critical Care Nursing (2004) defines critical care as "highly-specialized nursing care in cases of sudden life-threatening situations for all types of medical treatments and care and for all stages of illness and disease states, with the aim of improving chances of survival and quality of life (QOL)" [16]. Referencing the definition of The Japan Academy of Critical Care Nursing, in this study, a "person in a critical life situation" means a person who is in a critical life-threatening condition in a medical treatment context, including ambulances, hospital wards, emergency centers, and intensive care units.

\subsection{Aim}

The aim of this study was to shed light on the constructs that support decision-making in a critical life situation by both families and by medical staff, by analyzing concepts linked to family decision-making when choosing treatment in critical life situations, and using those results to investigate decision-making by families of the elderly in critical life situations.

\section{Research Method}

\subsection{Data Collection}

1) Literature search in Japanese

On March 15, 2017, we conducted a search of Japanese-language literature, using the keywords "emergency," "critical care," "elderly," and "family" in publications with the words "decision" and "nursing" in the title that were listed in Version 5 of the online version of Igaku chuo zasshi (published by the Japan Medical Abstracts Society). Our search was limited to articles published between 1997 and 2016.

We found 233 publications containing the keywords "emergency," "family," "decision," and "nursing," 116 containing "critical care," "family," "decision," and "nursing," 24 publications containing "critical care," "elderly," "decision," and "nursing," and 59 containing the keywords "emergency," "elderly," "decision," and "nursing." After excluding duplicates, we found 336 articles, of which 104 were original research articles. After excluding special commentary features, minutes of meetings, journals of regional academic associations, Collected Papers of Japan Nursing Association, technical journals, and journals of hospitals, 13 articles in which a patient's family's decision-making process (including emergency room treatment care) were selected for analysis. The selected articles 
reported on qualitative research concerning decision-making by families of patients in the emergency and critical care fields. We conducted the same search on the CiNii database, on March 31, 2017, but found no hits. When we changed the keywords, however, we found 16 articles containing "emergency patient" and "family," and five containing "ICU patient" and "family"; these were all duplicates of articles already found.

A search containing the keywords "emergency transportation" and "family nursing" was conducted using Igaku chuo zasshi (online version Ver. 5), on May 1, 2017, rendering 149 results. After exclusion of duplicates, two articles were added to the corpus. Another article was found through internet search, bringing the total number of articles selected for analysis to 16 (Figure 1).

2) Literature search of publications outside of Japan

For articles published outside of Japan, we conducted additional searches on the English-language medical database PubMed, because it can link to the information, summaries, and full text on the location of the paper. Our search included articles published from 1975 to 2016. A search of "Emergency" + "Surrogate Decision Making" rendered 69 articles, but none of them were relevant to our study. A search of "Critical care" + "Surrogate Decision-Making" found 212 articles after excluding duplicates, of which two were relevant to our study and were therefore included in the analysis. This search was performed on March 31, 2017. Final searches were conducted on April 14, 2017. A search of "Emergency," "Decision Making," "Family," and "Nursing" yielded 152 articles, and a search of "Critical care," "Decision Making," "Family," and "Nursing" another 475 articles after excluding duplicates, of which 11 were relevant to our study. The selected articles was qualitative research concerning decision-making by families of patients in the emergency and critical care fields, In addition, full text and articles available from journals were used. A total of 13 foreign-language publications were selected for analysis (Figure 1).

\subsection{Analysis}

Articles selected for analysis reported on qualitative research, focusing on families involved in treatment choices. In accordance with Rodgers' concept analysis approach, we extracted the attributes that contributed to constructs of the concept, antecedents that occurred before the concept, and consequences that arose subsequent to the concept.

In the case of literature without sub-categories, we extracted and coded content describing family decision-making and support from medical staff for decision-making and categorized it, considering commonalities and differences. Where literature objectively described sub-categories in detail (so as to allow for the same level of extraction), we similarly coded the data from the sub-categories contained in the literature, assigned it to categories, and studied the relationships among the antecedents, attributes, and consequences. In order to ensure the suitability of the analysis, doctoral candidates discussed their views under the 


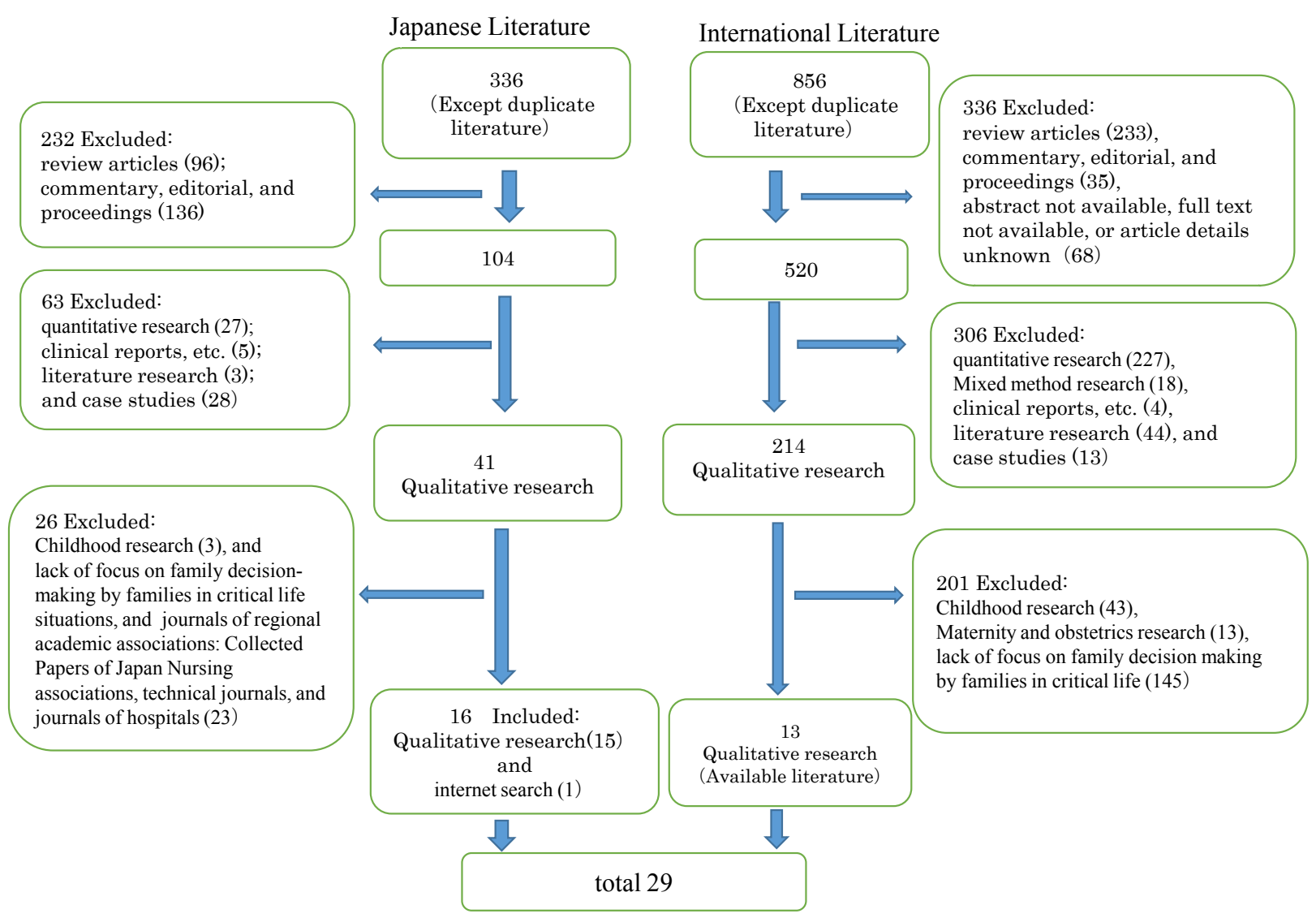

Figure 1. Process of selecting articles for analysis.

supervision of qualitative researchers. At the time of analysis, we exchanged opinions among doctoral students, who were supervised by qualitative researchers, repeated examinations, and tried to ensure credibility.

\section{Results}

A total of 29 publications were selected for analysis, 16 of which were Japanese, and 13 published outside of Japan. Total number of codes generated was 499; 24 were excluded as they were considered to relate to the thoughts of nurses themselves and did not directly affect family decision-making. Analysis was performed on 210 codes related to family choice of treatment and 265 relating to support from medical staff. Figure 2 shows the concept model of the antecedents, attributes and consequences obtained from the concept analysis.

In the following subsections we discuss the results from coding and categorization. Categories are indicated by [ ], sub-categories by $\langle<>>$, and codes by $<>$.

\subsection{Attributes}

We extracted five attributes of families as decision-makers and added one concept of medical staff supporting families' decision-making, for a total of six categories. The attributes are contained in Table 1. 
Table 1. Six attributes of decision-making by family members and medical staff.

\begin{tabular}{|c|c|c|}
\hline Categories & Subcategories & Literature \\
\hline $\begin{array}{l}\text { Decision-making in } \\
\text { the unusual setting }\end{array}$ & The context of the critical care unit & Ishizuka \& Inoue 2015 \\
\hline $\begin{array}{l}\text { of the critical care } \\
\text { unit with little time } \\
\text { to do so }\end{array}$ & $\begin{array}{l}\text { Lack of time, because of the seriousness } \\
\text { of the condition }\end{array}$ & Abe et al. 2007; Aiura \& Kuroda 2006; Wiegand 2008; Yokobori et al. 2012 \\
\hline Decision-making & Feeling regretful and responsible & Ishizuka \& Inoue 2015; Iwai et al., 2013; Suzuki et al. 2004; Yokobori et al. 2012 \\
\hline $\begin{array}{l}\text { in an unstable } \\
\text { psychological state }\end{array}$ & Mental agitation & Eguchi 2012; Ishizuka \& Inoue 2015; Suzuki et al. 2004, Yokobori et al. 2012 \\
\hline $\begin{array}{l}\text { while conscious of } \\
\text { their own }\end{array}$ & $\begin{array}{l}\text { Anxiety because of uncertainty about } \\
\text { the future }\end{array}$ & $\begin{array}{l}\text { Abe et al. 2007; Dionne-Odom et al. 2015; Eguchi 2012; Iwai et al. 2013; } \\
\text { Suzuki et al. } 2004\end{array}$ \\
\hline responsibility & Composed demeanor & Suzuki et al. 2004 \\
\hline
\end{tabular}

Deliberating deeply Thinking about the basis of the medical on the patient's prognosis, their relationship with the patient, and what they believe the patient would want situation

Mirr 1991; Schenker et al. 2012; Wiegand 2008

Thinking from the viewpoint of the current status of family relationships

Thinking about the financial resources Not knowing the patient's wishes

Aiura \& Kuroda 2006; Eguchi 2012; Mirr 1991

Mirr 1991

Ishizuka \& Inoue 2015

Abe et al. 2007; Buchman et al. 2003; Dionne-Odom et al. 2015; Eguchi 2012; Seeking emotional support from medical staff in the decision-making process

Wanting an understandable explanation and empathy with their feelings Frivold et al. 2015; Ishizuka \& Inoue 2015; Kryworuchko et al. 2012;

Morphet et al. 2015; Noome, et al., 2016; Schenker et al. 2012; Suzuki et al. 2004; Yokobori et al. 2012

Feeling reassured when medical staff are close at hand

Abe et al. 2007; Ishizuka \& Inoue 2015; Kato et al. 2015; Yokobori et al. 2012

Trusting medical staff and leaving everything to them

Aiura \& Kuroda 2006; Hall et al. 2008; Kato et al. 2015; Suzuki et al. 2004; Yokobori et al. 2012

Deciding as the person responsible for the family

Aiura \& Kuroda 2006; Ishizuka \& Inoue 2015; Kato et al. 2015;

Yokobori et al. 2012

Taking other family Making decisions by agreement, after members' views discussion within the family

Aiura \& Kuroda 2006; Buchman et al. 2003; Frivold et al. 2015; Ishizuka \& Inoue 2015; Mirr 1991; Schenker et al. 2012; Suzuki et al. 2004; Wiegand 2008

into account in decision-making

Making decisions in discussion with the medical team

Buchman et al. 2003; Wiegand 2008

Conjecturing about the patient's own wishes

Buchman et al. 2003; Hall et al. 2008; Ishizuka \& Inoue 2015; Schenker et al. 2012; Toim et al. 2012; Yokobori et al. 2012

Checking for the existence of a legal decision-maker

Mirr 1991; Morphet et al. 2015

Empathizing with the difficulty of decision-making by family members

Ishizuka and Inoue, 2015; Kryworuchko et al., 2016; Kryworuchko et al., 2012; Michael et al., 2015; Satake et al., 2015; Uesawa and Nakamura, 2013; Yajima and Nakamura, 2015; Yokobori et al., 2012; Yoshida and Nakamura, 2014

Empathizing with the difficulty of decision-making and monitoring the decision-making process while building relationships with family members

Noticing mental and physical effects on Moriki and Akashi, 2011; Satake et al., 2015; Uesawa and Nakamura, 2013; family members Yajima and Nakamura, 2015; Yokobori et al., 2012

Adams et al., 2014; Ishizuka and Inoue, 2015; Kryworuchko et al., 2016;

Watching the suffering involved during Kryworuchko et al., 2012; Kyogaku et al., 2009; Michael et al., 2015;

a decision-making process as the basis Moriki and Akashi, 2011; Nakamura et al., 2013; Satake et al., 2015; of a relationship of trust

Uesawa and Nakamura, 2013; Yajima and Nakamura, 2015;

Yoshida and Nakamura, 2014; Yokobori et al., 2012

Aiura and Kuroda, 2006; Ishizuka and Inoue, 2015; Kryworuchko et al., 2012;

Respecting decision-making by family Michael et al., 2015; Moriki and Akashi, 2011; Nakamura et al., 2013; Yajima and members Nakamura, 2014 


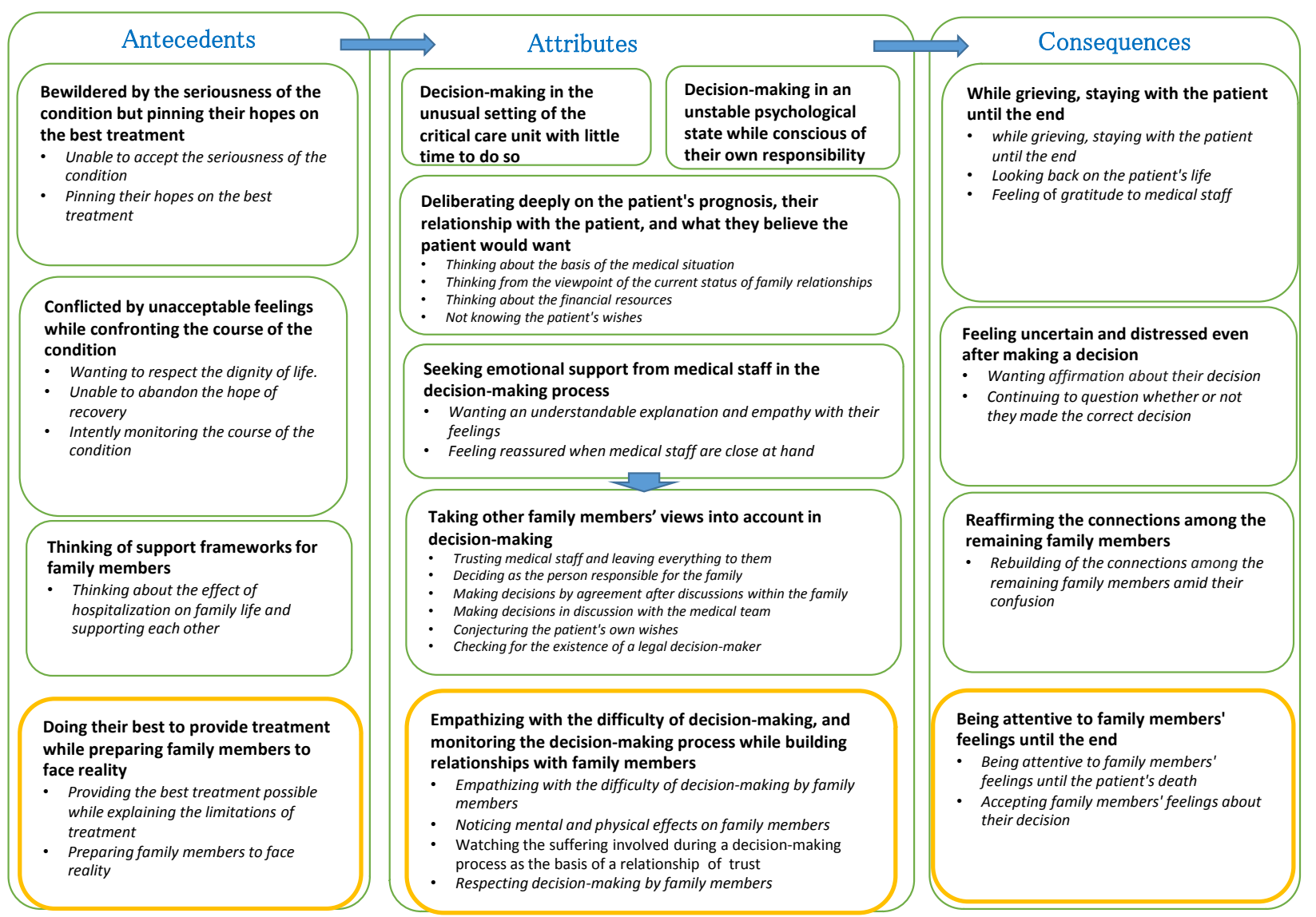

Figure 2. The concept model of the Decision-Making by Families in Critical Life Situations.

1) [Decision-making in the unusual setting of the critical care unit with little time to do so]

Two sub-categories were extracted as factors affecting decision-making: $<<$ the context of the critical care unit $>>$ [17], and $<<$ lack of time, because of the seriousness of the condition $>>$ [9] [17] [18] [19] [20]. The factors that were extracted were the critical care setting, which was out of the ordinary for families, and the situation, during which there was limited time for decision-making.

2) [Decision-making in an unstable psychological state while conscious of their own responsibility]

Sub-categories relating to unstable psychological state of families who are making decisions were: <<feeling regretful and responsible>> [17] [20] [21] [22], $<<$ mental agitation $>>$ [17] [20] [22] [23], and $<<$ anxiety because of uncertainty about the future $>>$ [18] [21] [22] [23] [24], <composed demeanor $>>$ [22].

3) [Deliberating deeply on the patient's prognosis, their relationship with the patient, and what they believe the patient would want]

As factors relating to judgment in the decision-making process, we extracted $<<$ thinking about the basis of the medical situation $>>$ [19] [25] [26], $<<$ thinking from the viewpoint of the current status of family relationships $>>$ [9] [23] [25], $<<$ thinking about financial resources $>>$ [25], and $<<$ not knowing the patient's wishes $>>$, stemming from $<$ not having had the discussion about end of life $>$ [17]. 
4) [Seeking emotional support from medical staff in the decision-making process]

As factors relating to families seeking emotional support from medical staff in the decision-making process, we extracted $<<$ wanting an understandable explanation and empathy with their feelings $>>$ [17] [18] [20] [22] [23] [24] [26]-[31] and $<<$ feeling reassured when medical staff are close at hand $>>$ [8] [17] [18] [20].

5) [Taking other family members' views into account in decision-making]

We extracted six sub-categories related to decision-making style. They were: $<<$ trusting medical staff and leaving everything to them >> [8] [9] [20] [32], $<<$ deciding as the person responsible for the family $>>$ [8] [9] [17] [20], $<<$ making decisions by agreement, after discussion within the family $>>$ [9] [17] [19] [22] [25] [26] [27] [28], <<making decisions in discussion with the medical team $>>$ [19] [27], and $<<$ conjecturing about the patient's own wishes $>>$ [17] [20] [26] [27] [32] [33]. In addition, we extracted <<checking for the existence of a legal decision-maker $>>$ [25] [30].

6) [Empathizing with the difficulty of decision-making, and monitoring the decision-making process while building relationships with family members]

We extracted four sub-categories relating to support from medical staff. Regarding decision-making support, we extracted factors relating to the difficulty of observing thoughts and feelings, <<empathizing with the difficulty of decision-making by family members $>>$ [17] [20] [29] [34]-[39], and $<<$ noticing mental and physical effects on family members $>>$ [20] [36] [37] [38] [40]. We also extracted attitudes of $<<$ watching the suffering involved during a decision-making process as the basis of a relationship of trust $>>$ [17] [20] [29] [34]-[43] and <<respecting decision-making by family members $>>$ [9] [17] [20] [29] [35] [37] [38] [39] [40] [43] while monitoring families' decision-making processes.

\subsection{Antecedents}

Antecedents are the events that occur before concepts. Four categories were extracted.

1) [Bewildered by the seriousness of the condition but pinning their hopes on the best treatment]

As antecedents regarding the patient's critical life situation, we extracted the feeling <<unable to accept the seriousness of the condition>> [18] [19] [20] [21] [22] [32], and $<<$ pinning their hopes on the best treatment $>>$ [8] [17] [21] [22] [23] [24] [25] [27] [33].

2) [Conflicted by unacceptable feelings while confronting the course of the condition]

When the patient's condition was right in front of their eyes, family dimensions were revealed, such as, $<<$ wanting to respect the dignity of life $>>$ [8] [17] [20] [24] [33], <<unable to abandon the hope of recovery $>>$ [8] [17] [19] [20] [21] [24] [26], and <<intently monitoring the course of the condition>> [17] [18] [19] [22] [30] [31]. 
3) [Thinking of support frameworks for family members]

The sub-category $<<$ thinking about the effect of hospitalization on family life and supporting each other $>>$ [20] [22] was extracted, signifying the way family roles are impacted by the hospitalization, as well as its economic effects.

4) [Doing their best to provide treatment while preparing family members to face reality]

$<<$ Providing the best treatment possible while explaining the limitations of treatment $>>$ [20] [36] [37] [40] [42] [43] was extracted, representing the sincere attitudes of medical staff to help family members understand the seriousness of the patient's medical condition, and the attitudes and responsibilities of the medical staff in relation to the limitations of medical treatment. Medical staff, by <providing time with the patient through visits> [17] [37] [38] [40], <participating in care together $>$ [28] [36] [38], <providing an opportunity to tour emergency care facilities $>$ [39] [43], and so on, provide support by $<<$ preparing family members to face reality $>$.

\subsection{Consequences}

Consequences are events that occur as a result of concepts. Four categories were extracted.

1) [While grieving, staying with the patient until the end]

After the decision has been made, attitudinal consequences include $<<$ while grieving, staying with the patient until the end $>>[20][31],<<$ looking back on the patient's life $>>$ [20], and $<<$ feelings of gratitude to medical staff $>>$ [20].

2) [Feeling uncertain and distressed even after making a decision]

Families <<wanting affirmation about their decision $>>$ [8] [9] [17] [20] and $<<$ continuing to question whether or not they made the correct decision $>>[8]$ [9] [17] [19] [33] were extracted, reflecting their anguish after the decision had been made.

3) [Reaffirming the connections among the remaining family members]

We extracted $<<$ rebuilding of the connections among the remaining family members amid their confusion $>>$ [9] [17] [19] [20] [23] as families reaffirmed their connection while continuing to suffer after making the decision, and their resolve to carry on.

4) [Being attentive to family members' feelings until the end]

We extracted sub-categories describing the resolve on the part of medical staff to stay with the families until the end, $<<$ being attentive to family members' feelings until the patient's death $>>$ [17] [36] [38], and <<accepting family members' feelings about their decision $>>$ [17] [20] [27] [39].

\section{Discussion}

\subsection{Concepts Related to Family Decision-Making When Choosing Treatment in Critical Life Situations}

Families who become the decision-makers in critical life situations, in the extraordinary environment of the critical care unit, with time restrictions, and in 
psychologically unstable states, come to their decisions by taking other family members' views into consideration, and considering such factors as information provided by medical staff regarding the patient's prognosis, the relationship with the patient, and conjectures as to what the patient would want. However, it has become clear that the process of arriving at a decision is not easy, and that families suffer even after the decision has been made. These findings suggest that how the decisions are made affects the rebuilding of relationships among the remaining family members.

Support from medical staff occurs throughout the process. Regarding family nursing provided by nurses in emergency and critical care, Yamase and colleagues extracted seven practical categories from the family needs listed in the Critical Care Family Assistance Program (CCFAP) and Coping and Needs Scale for Family Assessment in Critical and Emergency Care Settings, clearly demonstrating that the actual practice of family nursing in emergency and critical care areas is to "set the stage, get involved directly with the family, and ultimately follow a process of respecting the intentions of the family and supporting their actions." [44] Their findings suggest that support from medical staff in critical life situations reflects the structure of caring in the practice of family nursing in the fields of emergency and critical care [44].

\subsection{Potential Applications of "Concepts of Treatment Decisions in Critical Life Situations by Family" in Geriatric Care}

When a person is in a critical life situation, it is difficult to confirm their wishes. We extracted [deliberating deeply on the patient's prognosis, their relationship with the patient, and what they believe the patient would want] as factors in decision-making by families. These factors are partly driven by the family "not knowing the patient's wishes," because "few families have discussed death, even if they live in the same house together." [17] The United States instituted a legal framework for advance directives in 1990, while in Japan, the Ministry of Health, Labor, and Welfare issued its revised "Guidelines on the Decision-Making Process in End-of-Life Care," [5] which incorporates the concept of advance care planning (ACP). Advance directives have not been widely used in Japan, however, and from the standpoint of visiting nurses, Japan's elderly do not even attempt to make decisions about their own lives; even when they have a concept of what it means to be alive, they do not have a concept of what it means to die [45]. While we can expect that utilization of ACP will become widespread in future, it has been predicted that by 2025 there will be 7 million, or one in five, elderly with dementia [46]. Therefore, it will become necessary to interrogate the effectiveness of advance directives and to discern how much a patient has really understood, and whether they have indicated their wishes. In some cases where family patterns differ from the traditional Japanese family model, for example in quasi-families where an acquaintance has supported the patient for many years, or where there is no legally-registered relationship, it may become unclear who the decision-maker should be [47]. It is therefore important to consider the ef- 
fect of the Japanese cultural context on the difficulties that families of the elderly face when making decisions. When supporting decision-making, it is critical for medical staff to assess the context of family relationships, the extent to which the family understands the patient's wishes, and what their thinking process is as they arrive at their decision.

There are not many research related to the choice of treatment by families of geriatric patients in critical life situations in Japan. This study led to a "concept of decision-making by families in critical life situations" by systematic reviewing previous studies without singling out geriatric patients.

Based on the concepts extracted from this study, we will conduct research targeting elderly patients families in critical situations in Japan.

\subsection{Limitations of This Study}

This study was carried out as a concept analysis, following Rodgers' concept analysis approach. Rodgers recommends that researchers look at 30 relevant publications in order to shed light on concept constructs [15]. However, for this study we could only include 29 publications, those studying decision-making by families when choosing medical treatment in critical life situations combined with those studying support from medical staff. Therefore, it cannot be deduced that the study reflects the entire construct of the concept. Furthermore, the study was limited in that there were differences in the extent of disease states and progress of treatment in the critical life situations described in the literature.

\section{Conclusion}

In this concept analysis, we extracted six attributes, four antecedents and four consequences. The concepts involved in decision-making by families choosing treatment in critical life situations describe the process by which, under the conditions of the [unusual setting of the critical care unit], [the lack of time], and their [psychologically unstable state], families deliberate deeply on the [patient's prognosis], their [relationship with the patient], [conjecture as to what the patient would want], and [take other family members' views into account] in order to arrive at a decision. The medical staff supports the family throughout the process, by providing treatment, preparing family members to face reality, empathizing with the difficulty of decision-making, building relationships with family members, monitoring the decision-making process, and being attentive to family members' feelings until the end.

\section{Funding}

This research did not receive any specific grant from funding agencies in the public, commercial, or not-for-profit sectors.

\section{Conflicts of Interest}

The authors declare no conflicts of interest regarding the publication of this paper. 


\section{References}

[1] Fire and Disaster Management Agency (2017) Press Materials on Status of Ambulance and Rescue Services in 2017. Key Points, 4.

https://www.fdma.go.jp/neuter/topics/houdou/h29/12/291219_houdou_2.pdf

[2] Fire and Disaster Management Agency (2017) Status of Ambulance and Rescue Services in 2017. Ambulance Services, 18. https://www.fdma.go.jp

[3] Andou, D. (2009) Emergency Medicine for the Elderly: The Current Status of Elderly Critical Care. MOD Physician, 29, 1375-1378.

[4] Ministry of Health, Labour, and Welfare (2018) Investigative Commission on the Shape of Public Awareness Campaigns on Healthcare at the End of Life: Commentary on the Guidelines on the Decision-Making Process in End-of-Life Care, 5.

[5] Shinohara, Y., Azuma, F., Motoi, Y., Okayama, K., Imanishi, K., Higashiwaki, H., Kurihara, S., Hirosaki, R., Haba, Y. and Yamauchi, Y. (2011) A Discussion of the Role of Nurses in Decision-Making by Families of Emergency Patients: Through Cases of Differences in Opinion within Families. Emergency Care, 24, 401-405.

[6] Suzuki, K. and Hirai, K. (2008) The Experience of a Family Member of a Cancer Patient Urgently Admitted to the ICU Who Was Required to Make a Rapid Decision on Treatment Policy: Through an Interview with a Mother Who Made the Surrogate Decision to Fit an Artificial Ventilator. Collected Papers of Japan Nursing Association, Adult Nursing (Nihon Kango Gakkai Ronbunshu Seijin Kango) I, 39, 184-186.

[7] Sasaki, Y. (2004) Involvement in Decision-Making by Family Members on Life-Extending Care: A Consideration of the Role of Nurses in Acute Wards. The Japanese Journal of Clinical Nursing Art and Science, 11, 29-37.

[8] Kato, A., Tado, A. and Yamase, H. (2015) How Families Attach Meaning to Death in Critical Care Settings. Journal of Japanese Association for Emergency Nursing, 17, 56-66. (In Japanese)

[9] Aiura, K. and Kuroda, Y. (2006) Decision on the Treatment Made by Family as Substitute of Critically Ill Patient. Journal of Japan Academy of Critical Care Nursing, 2, 75-83. (In Japanese)

[10] Tatsuno, J., Yamase, H., Tado, A. and Fujita, N. (2014) End-of-Life Care in the ICU, and Recognition of the Medical Staff. Journal of Japan Academy of Critical Care Nursing, 10, 23-33.

[11] Wendler, D. and Rid, A. (2011) Systematic Review: The Effect on Surrogates of Making Treatment Decisions for Others. Annals of Internal Medicine, 154, 336-46. https://www.ncbi.nlm.nih.gov/pubmed/21357911 https://doi.org/10.7326/0003-4819-154-5-201103010-00008

[12] Hitai, R. (2012) Through Engagement with a Case in Which Differences of Opinion between Surrogate Decision-Makers Were Evident. Journal of Japanese Association for Emergency Nursing, 14, 77.

[13] Sakuraba, A., Narita, M. and Kimura, N. (2015) Special Issue. When, Where, and How to Give Support? Nursing Geriatric Patients. Support for Decision-Making by Family Members on Life-Extending Treatment of Geriatric Patients. Japan Journal of Nursing Science, 40, 42-46.

[14] Kaneko, N. (2011) Present Status and Controversies on Ambulance Transport of Elderly Patients from Viewpoint of Emergency Medical Center, Dai 53 Kai Nihon Ronen Igakugaakai Gakujutsu Shukai Kiroku_Kyoikukoen. Nihon Ronen Igakkai Zasshi, 48, 478-481. 
[15] Rodgers, B.L. (2000) Concept Analysis: An Evolutionary View. In: Rogers, B.L. and Knafl, K.A., Eds., Concept Development in Nursing Foundations, Techniques, and Applications, 2nd Edition, Saunders, Philadelphia, PA, 77-102.

[16] Inoue, T. (2005) Chikuseki kara chosen he (From Accumulation to Challenge). Journal of Japan Academy of Critical Care Nursing, 1, 15-19.

[17] Ishizuka, K. and Inoue, T. (2015) Families' Thoughts Regarding Surrogate Decision-Making and Nursing Support in Critical Care. Journal of Japan Academy of Critical Care Nursing, 11, 11-23. [In Japanese]

[18] Abe, M., Shijiki, Y., Kawamura, S. and Suzuki, J. (2007) The Factors Related to the Decision-Making Made by Family Members in Emergency Medical Situations-from Family Nursing Perspective. The Journal of Japan Academy of Health Sciences, 9, 238-249. [In Japanese]

[19] Wiegand, D. (2008) In Their Own Time: The Family Experience during the Process of Withdrawal of Life-Sustaining Therapy. Journal of Palliative Medicine, 11, 1115-1121. https://doi.org/10.1089/jpm.2008.0015

[20] Yokobori, J., Inoue, T. and Sasaki, Y. (2012) Experiences of Patient's Families and Recognitions among Healthcare Providers Who Make Decisions for Withhold of Life-Sustaining Treatments in the Emergent Critical Care Unit. Journal of Japanese Association for Emergency Nursing, 14, 10-20. [In Japanese]

[21] Iwai, A., Ogawa, R. and Osada, K. (2013) Feelings of Families between the Decision of Hospitalization and Time of Entering the ICU. Bulletin of Shimane University Faculty of Medicine Shimane Daigaku Igakubu kiyo, 36, 55-60. [In Japanese]

[22] Suzuki, K., Toyoda, T., Nagase, M., Shikimori, H. and Murata, H. (2004) Experiences of and Care for Families of ER Ambulance-Borne Patients Based on Characteristic of Family Cognition and Behavior. Tokai University, School of Health Sciences Bulletin, 9, 11-18. [In Japanese]

[23] Eguchi, H. (2012) Experiences of Families of Emergency Patients in Their Words and Giving Meaning to Them. Konan Women's University Researches. Studies in Nursing and Rehabilitation, 6, 51-60. [In Japanese]

[24] Dionne-Odom, J.N., Willis, D.G., Bakitas, M., Crandall, B. and Grace, P.J. (2015) Conceptualizing Surrogate Decision Making at End of Life in the Intensive Care Unit Using Cognitive Task Analysis. Nursing Outlook, 63, 331-340.

https://doi.org/10.1016/j.outlook.2014.10.004

[25] Mirr, M.P. (1991) Decisions Made by Family Members of Patients with Severe Head Injury. AACN Clinical Issues in Critical Care Nursing, 2, 242-251. https://doi.org/10.4037/15597768-1991-2009

[26] Schenker, Y., Crowley-Matoka, M., Dohan, D., Tiver, G.A., Arnold, R.M. and White, D.B. (2012) I Don't Want to Be the One Saying 'We Should Just Let Him Die': Intrapersonal Tensions Experienced by Surrogate Decision Makers in the ICU. Journal of General Internal Medicine, 27, 1657-1665. https://doi.org/10.1007/s11606-012-2129-y

[27] Buchman, T.G., Ray, S.E., Wax, M.L., Cassell, J., Rich, D. and Niemczycki, M.A. (2003) Families' Perceptions of Surgical Intensive Care. American College of Surgeons, 196, 977-983. https://doi.org/10.1016/S1072-7515(03)00294-1

[28] Frivold, G., Dale, B. and Slettebø, Å. (2015) Family Members' Experiences of Being Cared for by Nurses and Physicians in Norwegian Intensive Care Units: A Phenomenological Hermeneutical Study. Intensive and Critical Care Nursing, 31, 232-240. https://doi.org/10.1016/j.iccn.2015.01.006

[29] Kryworuchko, J., Stacey, D., Peterson, W.E., Heyland, D.K. and Graham, I.D. (2012) 
A Qualitative Study of Family Involvement in Decisions about Life Support in the Intensive Care Unit. American Journal of Hospice and Palliative Medicine, 29, 36-46. https://doi.org/10.1177/1049909111414176

[30] Morphet, J., Decker, K., Crawford, K., Innes, K., Williams, A.F. and Griffiths, D. (2015) Aged Care Residents in the Emergency Department: The Experiences of Relatives. Journal of Clinical Nursing, 24, 3647-3653. https://doi.org/10.1111/jocn.12954

[31] Noome, M., Dijkstra, B.M., Van Leeuwen, E. and Vloet, L.C. (2016) Exploring Family Experiences of Nursing Aspects of End-of-Life Care in the ICU: A Qualitative Study. Intensive and Critical Care Nursing, 33, 56-64. https://doi.org/10.1016/j.iccn.2015.12.004

[32] Hall, P., Sanford, J.T. and Demi, A.S. (2008) Patterns of Decision Making by Wives of Patients with Life-Threatening Cardiac Disease. Journal of Family Nursing, 14, 347-336. https://doi.org/10.1177/1074840708322235

[33] Toima, M., Shono, I., Eguchi, C. and Fujimoto, T. (2012) Significance and Effect of Therapeutic Questions to Family Members Agonizing over Decisions on the Treatment of Patients in Critical Conditions, with a Focus on Belief. Journal of Japanese Society for the Study of Nursing and Social Work, 17, 119-134. [In Japanese]

[34] Kryworuchko, J., Strachan, P.H., Nouvet, E., Downar, J. and You, J.J. (2016) Factors Influencing Communication and Decision-Making about Life-Sustaining Technology during Serious Illness: A Qualitative Study. BMJ Open, 6, e010451. https://doi.org/10.1136/bmjopen-2015-010451

[35] Michael, K., Ilana, K. and David, C. (2015) Being a Legal Guardian-The Nursing Perspective. Israel Journal of Health Policy Research, 24, 59.

[36] Satake, Y., Nitta, N. and Urade, S. (2015) Nursing Practice by Expert Nurses for the Families of Terminal Stage Patients in the Emergency Room. Journal of Japanese Association for Emergency Nursing, 17, 24-34. [In Japanese]

[37] Uesaw, H. and Nakamura, M. (2013) Difficulties of Nurses Who Are Involved in Family's Surrogate Decision-Making for an Emergency Patient and Their Reasons. Journal of Japan Academy of Critical Care Nursing, 9, 6-18. [In Japanese]

[38] Yajima, M. and Nakamura, M. (2015) Characteristics of Patients with Do Not Attempt Resuscitation (DNAR) Notices and Their Families of Which Nurses Are Aware and Nursing Practice for Family Members. Journal of Japanese Association for Emergency Nursing, 17, 35-44. [In Japanese]

[39] Yoshida, N. and Nakamura, M. (2014) Expert Critical Care Nurses' Practices to Assist Patients' Families with Surrogate Decision-Making Regarding Life-Sustaining Treatment. Journal of Japanese Association for Emergency Nursing, 16, 1-12. [In Japanese]

[40] Moriki, Y. and Akashi, K. (2011) The Meaning of Help by Nurses for Families of Emergency Patients. Journal of Japanese Association for Emergency Nursing, 13, 10-18. [In Japanese]

[41] Adams, J.A. Anderson, R.A., Docherty, S.L., Tulsky, J.A., Steinhauser, K.E. and Bai-ley Jr., D.E. (2014) Nursing Strategies to Support Family Members of ICU Patients at High Risk of Dying. Heart \& Lung. The Journal of Acute and Critical Care, 43, 406-415. https://doi.org/10.1016/j.hrtlng.2014.02.001

[42] Kyogaku, S., Sone, K., Aitake, M. and Yatuzuka, M. (2009) The Study of the Characteristic of Family Care in the Initial Management Room of the Emergency Center. Journal of Japanese Association for Emergency Nursing, 11, 33-40. [In Japanese] 
[43] Nakamura, M., Murakami, R. and Shimizu, R. (2013) Study of Decision-Making by Family Members to Prolong Life in Emergency Medical Treatment: The Process of Discussion between Family Members and Doctors. Journal of Japanese Association for Emergency Nursing, 15, 1-12. [In Japanese]

[44] Yamase, Y., Yamase, H. and Tatsuno, J. (2013) Structure Model of Family Nursing Provided by Nurses in Emergency and Critical Care. Yamaguchi Medical Journal, 62, 91-98.

[45] Takasuna, H. (2018) Special Issue. Nursing Engagement at the End of Life Interpreted through the Guidelines on the Decision-Making Process in End-of-Life Care. The Decision-Making Process on Treatment and Care in Light of Changes in $\mathrm{Pa}$ tients' Wishes. Japan Journal of Nursing Science, 43, 37-41.

[46] Cabinet Office (2017) Chapter 1: The Situation on Aging, Annual Report on the Aging Society [PDF Full Version]. 19-21.

https://www8.cao.go.jp/kourei/whitepaper/w-2017/html/zenbun/s1_2_3.html

[47] Itou, K. (2016) Special Issue on Decision-Making on Physical Treatment for Elderly Dementia Patients. Treatment of Physical Complications of Dementia. Clinical Issues with the Treatment of Physical Disorders in Dementia Patients. Japanese Journal of Geriatric Psychiatry, 27, 382-389. 